\title{
Increased PTPRA expression leads to poor prognosis through c-Src activation and G1 phase progression in squamous cell lung cancer
}

\author{
ZHIDONG GU ${ }^{1 *}$, XUQIAN FANG ${ }^{2 *}$, CHANG LI $^{1}$, CHANGQIANG CHEN $^{2}$, \\ GUANGSHU LIANG ${ }^{1}$, XINMING ZHENG ${ }^{1}$ and QISHI FAN ${ }^{2}$ \\ ${ }^{1}$ Department of Clinical Medicine, Ruijin Hospital, Jiaotong University School of Medicine, \\ Shanghai 200025; ${ }^{2}$ Department of Clinical Medicine, Ruijin Hospital North, \\ Jiaotong University School of Medicine, Shanghai 201801, P.R. China
}

Received January 24, 2017; Accepted June 19, 2017

DOI: $10.3892 /$ ijo.2017.4055

\begin{abstract}
PTPRA is reported to be involved in cancer development and progression through activating the Src family kinase (SFK) signaling pathways, however, the roles of PTPRA in the squamous cell lung cancer (SCC) development are unclear. The purpose of this study was to clarify the clinical relevance and biological roles of PTPRA in SCC. We found that PTPRA was upregulated in squamous cell lung cancer compared to matched normal tissues at the mRNA $(\mathrm{N}=20, \mathrm{P}=0.004)$ and protein expression levels $(\mathrm{N}=75$, $\mathrm{P}<0.001)$. Notably, high mRNA level of PTPRA was significantly correlated with poorer prognosis in $675 \mathrm{SCC}$ patients from the Kaplan-Meier plotter database. With 75 cases, we found that PTPRA protein expression was significantly correlated with tumor size $(\mathrm{P}=0.002)$, lymph node metastasis $(\mathrm{P}=0.008)$, depth of tumor invasion $(\mathrm{P}<0.001)$ and clinical stage $(\mathrm{P}<0.001)$. The Kaplan-Meier plot suggested that high expression of PTPRA had poorer overall survival in SCC patients $(\mathrm{P}=0.009)$. Multivariate $\mathrm{Cox}$ regression analysis suggested that PTPRA expression was an independent prognostic factor in SCC patients. In the cellular models, PTPRA promotes SCC cell proliferation through modulating Src activation as well as cell cycle progression. In conclusion, higher PTPRA level was associated with worse prognosis of SCC patients and PTPRA could promote the cell cycle progression through stimulating the c-Src signaling pathways.
\end{abstract}

Correspondence to: Dr Qishi Fan, Department of Clinical Medicine, Ruijin Hospital North, Jiaotong University School of Medicine, 888 Shuangding Road, Shanghai 201801, P.R. China

E-mail: qishifan@126.com

${ }^{*}$ Contributed equally

Key words: PTPRA, c-Src activation, squamous cell lung cancer, cell cycle progression, G1/S

\section{Introduction}

The elegant balance between protein tyrosine kinase (PTK) and protein tyrosine phosphatase (PTP) activities modulate the tumorigenic process through 'switch' diverse signaling pathways (1). Since the prevalent hypothesis is that active PTKs are oncogenes, PTPs are intuitively supposed to have tumor suppression potentiality. Indeed, PTPN12 (2) and PTPN23 (3) were shown to be key tumor suppressor genes in triple-negative breast cancer. In addition, PTPN13 (4) was identified as a suppressor of HER2-positive breast cancers through counteracting the HER2 activation. Loss of PTPN13 (4) and PTPRO (5) has been observed in hepatocellular carcinoma tissues. PTPRK (6), PTPN7 (7), and PTPN13 (4) are either mutated or downregulated in lymphoma, and depletion of DUSP1 (8) has been detected in ovarian cancers. In contrast, some PTPs may activate oncogenic pathways in human cancer cells and act as proto-oncogenes (9-12). For example, PTP1B is frequently overexpressed in various cancers including breast cancer, colon cancer, prostate cancer and gastric cancer. PTP1B has been demonstrated to promote cancer cell growth, migration and invasion both in vitro and in vivo (13). In some cases, PTPs may play opposite roles at different stage of the diseases or distinct types of human cancers, suggesting the complexity roles of PTPs in the cancer development and progression (14-16).

The receptor protein-tyrosine phosphatase $\alpha$ (encoded by PTPRA), a 130-kDa transmembrane PTP, has shown to be a physiological regulator for PTK c-Src $(17,18)$ and the kinases involved in integrin signaling pathway including FAK (19) and P130cas (20). The activation of PTPRA on Src Y530 dephosphorylation led to cellular transformation, which suggested that PTPRA might be an oncogenic gene. Overexpression of miR-218, a microRNA binds directly to the 3'-UTR of PTPRA decreased PTPRA protein leading to decreased dephosphorylation of c-Src and decreased tumor growth in vitro and in vivo (21).

Although cell line studies strongly support the role of PTPRA in cancer progression $(11,22)$, translational studies on PTPRA expression in human cancer expression and 
its correlation with activation and clinical parameters are surprisingly limited. On the contrary, there is abundant evidence showing that the levels of SFK or the activation states are elevated in various malignancies, such as the prostate, breast, colon and lung cancers (23-27). In this study, we demonstrated that the expression of PTPRA was elevated in a cohort of SCC cancers, and there was an association between PTPRA overexpression and poor survival in SCC cancer patients. Functional studies showed that PTPRA promoted lung cancer cell growth by modulating Src activation and cell progression.

\section{Materials and methods}

Immunohistochemical staining of PTPRA. Tissue microarray (TMA) assays were from Superchip (Shanghai, China). It consisted of 75 cases of the tissues for lung squamous cell carcinoma and its adjacent normal tissue (array ID: HLugSqu150Sur-01). The clinical information including tumor type, age, sex, tumor size, tumor location, TNM stage and the clinical stage were collected from the patients' medical records. Clinical staging was categorized according to the latest revision of American Joint Committee on Cancer. The follow-up time was calculated from the date of surgery to the date of death, or the last known follow-up date.

For the immuohistochemical (IHC) staining of the tissues, the $6-\mu \mathrm{m}$ sections were deparaffined with the dimethylbenzene and rehydrated with the gradient ethanol. The sections were treated with $3 \% \mathrm{H}_{2} \mathrm{O}_{2}$ to inactivate the internal catalase prior to antigen retrieval. The TMAs were incubated at $4{ }^{\circ} \mathrm{C}$ overnight after antigen retrieval with monoclonal anti-PTPRA antibodies (Millipore, USA; 1:300), non-phosphate/Src (Tyr527) (Cell Signaling Technology, USA; 1:2,000) or phosphate/Src (Tyr527) (Cell Signaling Technology; 1:200) antibodies. After the incubation, the protein expression level was visualized using a biotinylated secondary antibody with avidine-conjugated peroxidase (Novocastra Laboratories Ltd., Newcastle, UK) and its substrate DAB (H\&E counterstaining).

Aperio digital IHC analysis and guantification. Immunohistochemical staining was scored by Aperio ImageScope software with Aperio's Positive Pixel Count Algorithm (Aperio Technologies, Vista, CA, USA). TMA and the slides were scanned using the AperioScanScope System at x40 magnification to provide a high-resolution digital image. The ImageScope software was used to analyse and quantify the expression level of the biomarkers. ROI for individual tumor cores was detected and analysed using the positive pixel count algorithm according to the manufacturer's guidelines. For each case, two representative cores were screened and the averaged score was measured to provide a pixel count for any individual. In order to confirm the accuracy of the digital quantification, the TMAs were also evaluated with two independent pathologists according to the intensity and percentage of positive cells. The final score was designated as low or high expression group using the median ROI values of the TMA.

Besides TMAs, the routing paraffin sections were evaluated by two independent pathologists according to the intensity and percentage of positive cells, simultaneously. Staining intensity was scored as follows: 0 , negative; 1 , weak staining; 2 , moderate staining; 3 , strong staining, and the percentage of positive cells was also scored according to 4 categories, in which 1 was given for $0-25 \%, 2$ for $26-50 \%, 3$ for $51-75 \%$, and 4 for $76-100 \%$. Also, the final score was designated as low or high expression group using the percent of positive cell score multiply the staining intensity score as follows: low expression was defined as a total score $<4$ and high expression with a total score $\geq 4$.

$m R N A$ expression in lung cancer tissues. Freshly frozen lung cancer and the adjacent normal tissue samples were prospectively collected from patients who received surgery in the Ruijin North Hospital in the year 2015. Lung tissue samples were stored at $-80^{\circ} \mathrm{C}$ until use. Informed consent was obtained from each participating patient. Twenty paired freshly frozen primary lung cancer tissues and corresponding adjacent non-cancerous tissues were chosen to perform real-time PCR (RT-PCR). The gene-specific qPCR primers for detection of PTPRA (NM_002836.3) were forward, 5'-CAACAATGCT ACCACAGT-3', reverse, 5'-AAGAGAAGTTAGTGAAGAA GTT-3'. To verify the percentage of tumor cells, the frozen samples were embedded in Tissue-Tek OCT Compound (Sakura Finetek, Torrance, CA, USA) and $6-\mu \mathrm{m}$ frozen ice-sections were prepared and stained using hematoxylin. Histology of lung cancer specimens was evaluated by an experienced pathologist.

Cells and plasmid transfections. Human lung squamous cell carcinoma cell line NCI-H520 and human kidney cell line 293T were obtained from ATCC (Rockville, MD, USA). All cells were maintained in DMEM+10\% fetal bovine serum (FBS). Full length human PTPRA cDNA was cloned and inserted between the NheI and NotI sites of PCDH-513B-Puro lentiviral vector (System Biosciences, Canada). 293T cells were transfected with PCDH-513B/PTPRA or with PCDH-513B (control) using calcium phosphate, and retroviruses were collected after $48 \mathrm{~h}$. NCI-H520 cells were infected with PTPRA-expressing or control retroviruses and selected with $1 \mu \mathrm{g} / \mathrm{ml}$ puromycin.

Immunoblot analysis. Proteins were isolated using general procedures. Specimens were homogenized and lysed for $30 \mathrm{~min}$ on ice in RIPA (50 mM Tris pH 7.4, $150 \mathrm{mM} \mathrm{NaCl}, 1 \%$ Triton $\mathrm{X}-100,1 \%$ Na deoxycholate, $0.1 \%$ SDS, $1 \mathrm{mM} \mathrm{Na}_{3} \mathrm{VO}_{4}, 1 \mathrm{mM}$ PMSF, $10 \mathrm{mg} / \mathrm{ml}$ leupeptin, $10 \mathrm{mg} / \mathrm{ml}$ aprotinin). Whole-cell lysates containing $50 \mu \mathrm{g}$ of proteins, were separated by SDS-PAGE and immunoblotted with the following specific antibodies. Antibodies for Src, non-phosphate/Src (Tyr527), phosphate/Src (Tyr527) and phosphate/Src (Tyr419) were purchased from Cell Signaling Technology (USA). Antibody for the total PTPRA was purchased from Millipore. Antibodies for p21, cyclin D1, cyclin D3, p27 and p18 were detected with the Cell Cycle Sampler kit (Cell Signaling Technology). Antibodies were used at 1:1,000 dilutions according to the manufacturer's instructions. Western blotting was performed according to standard protocols.

Cell proliferation and cell cycle assays. Cell proliferation was determined by the MTT assay. In brief, cells infected with PTPRA-expressing or control retroviruses were seeded and 
Table I. Relationship between PTPRA expression and clinicopathological characteristics in 75 lung SCC patients.

\begin{tabular}{|c|c|c|c|}
\hline \multirow[b]{2}{*}{ Variable } & \multicolumn{2}{|c|}{ PTPRA } & \multirow[b]{2}{*}{ P-value } \\
\hline & High (47) & Low (23) & \\
\hline \multicolumn{4}{|l|}{ Age } \\
\hline$\leq 65$ years & 23 (48.94) & $13(56.52)$ & 0.5509 \\
\hline$>65$ years & $24(51.06)$ & $10(43.48)$ & \\
\hline \multicolumn{4}{|l|}{ Sex } \\
\hline Male & 43 (91.49) & $22(95.65)$ & 0.5253 \\
\hline Female & $4(8.51)$ & 1 (4.35) & \\
\hline \multicolumn{4}{|l|}{ Tumor site } \\
\hline Upper lung & $32(68.09)$ & $12(52.17)$ & 0.1956 \\
\hline Lower lung & $15(31.91)$ & $11(47.83)$ & \\
\hline \multicolumn{4}{|l|}{ Tumor size } \\
\hline$\leq 5 \mathrm{~cm}$ & $20(42.55)$ & $19(82.61)$ & 0.0015 \\
\hline$>5 \mathrm{~cm}$ & $27(57.45)$ & 4 (17.39) & \\
\hline \multicolumn{4}{|l|}{$\begin{array}{l}\text { Lymph node } \\
\text { metastasis }\end{array}$} \\
\hline Absent & $21(44.68)$ & $18(78.26)$ & 0.0079 \\
\hline Present & $26(55.32)$ & $5(21.74)$ & \\
\hline \multicolumn{4}{|c|}{$\begin{array}{l}\text { Depth of tumor } \\
\text { invasion }\end{array}$} \\
\hline $\mathrm{T} 1$ & $2(4.26)$ & $11(47.83)$ & $<0.0001$ \\
\hline $\mathrm{T} 2$ & 29 (61.70) & $9(39.13)$ & \\
\hline $\mathrm{T} 3$ and $\mathrm{T} 4$ & $16(34.04)$ & $3(13.04)$ & \\
\hline \multicolumn{4}{|l|}{ Clinical stage } \\
\hline I & $8(17.02)$ & $16(69.57)$ & \\
\hline II & $23(48.94)$ & $5(21.74)$ & $<0.0001$ \\
\hline III & $16(34.04)$ & $2 \quad(8.69)$ & \\
\hline
\end{tabular}

cultured in 96-well plates for 1, 3, 5 and 7 days. At the indicated times, $20 \mathrm{ml}$ of $0.5 \mathrm{mg} / \mathrm{ml}$ MTT (Sigma, St. Louis, MO, USA) was added into the medium and incubated for another $4 \mathrm{~h}$. The medium was removed and the $150 \mu \mathrm{l}$ DMSO was added. The plates were then tested with a microplate reader using the wavelength of $570 \mathrm{~nm}$ and a reference wavelength of $670 \mathrm{~nm}$. For cell cycle assay, stable cells infected with PTPRA-expressing or control vector were harvested at $24 \mathrm{~h}$ when the confluence reached $>80 \%$, and washed twice with PBS. Cells were then fixed with ice-cold $70 \%$ ethanol for $30 \mathrm{~min}$, and stained with propidium iodide solution $(50 \mathrm{mg} / \mathrm{ml}$ propidium iodide, $50 \mathrm{mg} / \mathrm{ml}$ RNase A, $0.1 \%$ Triton-X, $0.1 \mathrm{mM}$ EDTA). Cell cycle distributions were determined with a flow cytometer (BD Biosciences, NJ, USA).

Statistical analyses. Statistical analyses were performed by SPSS (version 19.0, USA). Continuous variables were analysed with the Student's t-test. Category variables were analysed with the Chi-square test. The survival rate was evaluated by Kaplan-Meier plot and differences between curves were tested with the log-rank test. For all tests, the significance level for statistical analysis was set at $\mathrm{P}<0.05$ for two-sided tests.

\section{Results}

Frequent elevation of PTPRA expression in human lung squamous cell carcinoma. As the roles of PTPRA in lung cancer development and progression were not clearly elucidated, we determined mRNA expression level of PTPRA in 20 pairs of SCC cancer and matched adjacent ( $\geq 5 \mathrm{~cm}$ distant) tissues with the quantitative RT-PCR (qRT-PCR) assays. We found that $80 \%$ (16 out of 20) of SCC tumors showed a $>2$-fold increment of the mRNA levels compared to the normal tissues (Fig. 1A). With the public database KMplot (28), which consisted of 2,436 lung patients, we found that patients with higher PTPRA expression were significantly associated with poorer overall survival (log-rank test, $\mathrm{P}=0.029$ ) and progression-free survival (log-rank test, $\mathrm{P}=0.008$; Fig. 1B). When we divided patient groups into squamous cell carcinoma and adenocarcinoma according to the lung pathology subtypes, it shows that the elevated PTPRA expression leads to a shorter progression-free survival in patients of squamous cell carcinoma $(\mathrm{P}=0.046)$ but not in the adenocarcinoma (Fig. $1 \mathrm{C}$ and D). These results suggested that PTPRA might play important roles in the progression of lung SCC.

Association of PTPRA high expression with poor prognosis of SCC patients. We further determined the associations of PTPRA expression and pathological characteristics with a tissue microarray that consisted of 75-paired SCC specimens and the corresponding normal samples. Compared to the normal adjacent tissue, the SCC tissues showed a significant increased expression of PTPRA ( $\mathrm{P}<0.001$; Fig. 2A-C). As shown in Table I, high expression of PTPRA was significantly correlated with tumor size $(\mathrm{P}=0.002)$, lymph node metastasis $(\mathrm{P}=0.008)$, depth of tumor invasion $(\mathrm{P}<0.001)$ and clinical stage $(\mathrm{P}<0.001)$.

The Kaplan-Meier plot suggested that patients with higher PTPRA expression were associated with poorer overall survival of SCC patients (log-rank test, $\mathrm{P}=0.009$; Fig. 2D and $\mathrm{E}$ ). Univariate analyses suggested that PTPRA level, age, lymph node metastasis and clinical stage were significantly associated with the OS of the SCC patients (Table II). The multivariate Cox regression analysis suggested that PTPRA expression (HR, 2.306; 95\% CI, 1.189-4.469) and age (HR, 2.895; 95\% CI, 1.430-5.859) were correlated with the OS for SCC patients. These results suggested that PTPRA was an independent prognostic factor for SCC patients.

PTPRA is correlated with c-Src activation in SCC samples. To investigate whether the overexpressed PTPRA protein plays a role on oncogene c-Src activation in vivo, we checked 30 cases of primary SCC, both stained with PTPRA antiserum, Src Tyr527 non-phosphorylation anti-serum and Src Tyr527 phosphorylation anti-serum by method of immunohistochemically staining. A typical sample is shown in Fig. 3A-F. The level of agreement between PTPRA expression and non-phosphate/Src (Tyr527) was evaluated using PABAK (prevalence-adjusted bias-adjusted kappa), the result of 0.61 indicates a substantial agreement (Fig. 3G). The correlation between PTPRA expression and c-Src activation was also checked in fresh frozen tissues. Analysis of a total of 20 matched normal neighbouring tissue samples, PTPRA expression was 
A

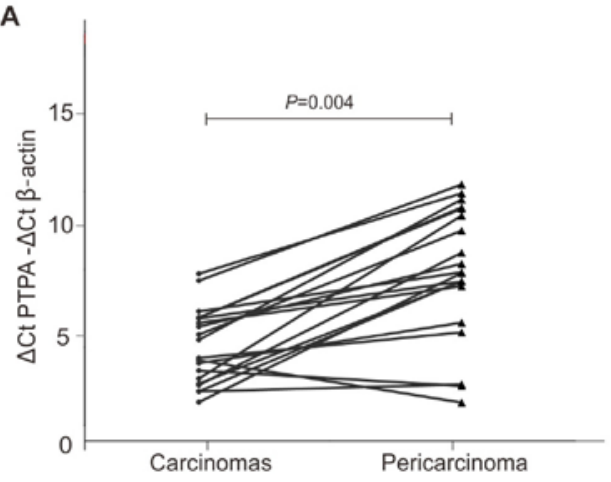

C

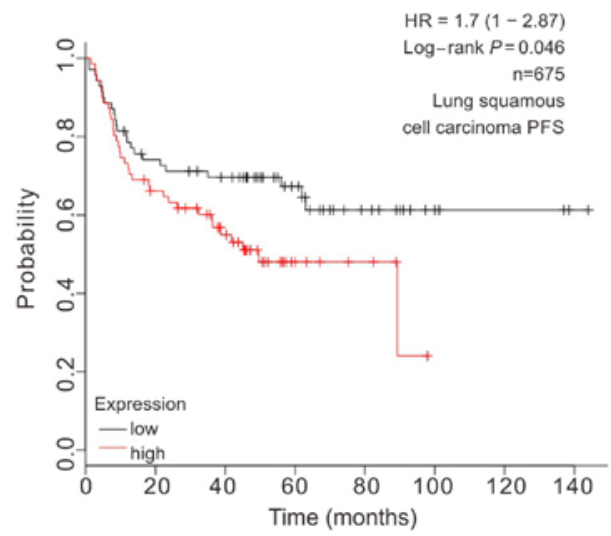

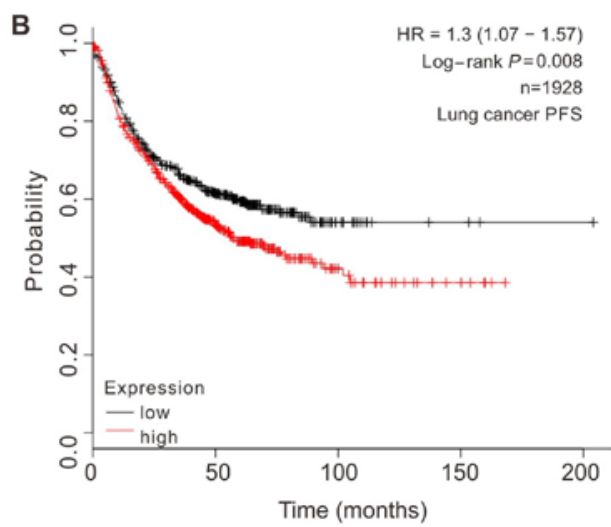

D

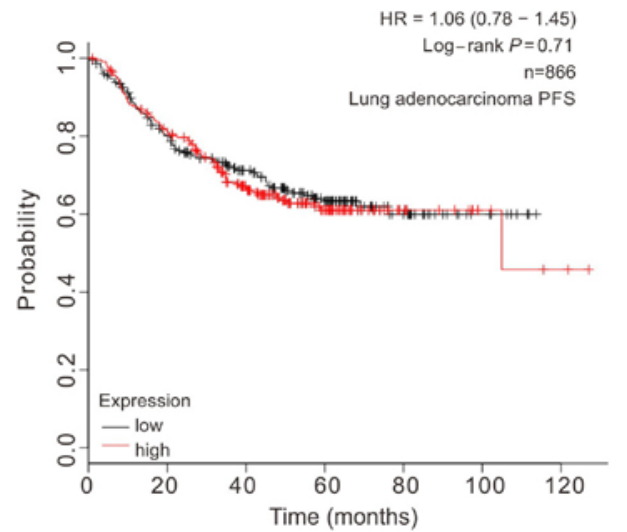

Figure 1. High PTPRA expression is correlated with poor prognosis in lung cancer patients at mRNA level. (A) Increased PTPRA mRNA expression in 20 matched SCC tumor (carcinomas) and non-tumor tissue (pericarcinomas) was detected by real-time quantitative PCR. P-value was calculated by paired t-test. (B) Kaplan-Meier plots showed high expression level of PTPRA was correlated with short PFS in lung cancer from KMplot database (log-rank P=0.008). (C and D) The correlation between of PTPRA expression and PFS in SCC or lung adenocarcinomas calculated from KMplot database.

A Lung SCC carcinoma

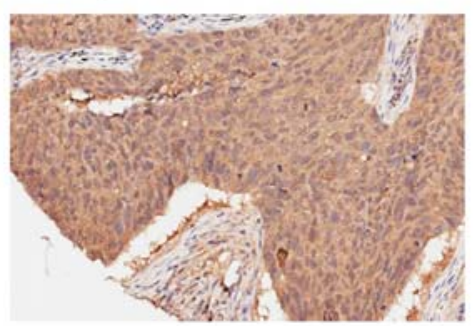

D High expression of PTPRA

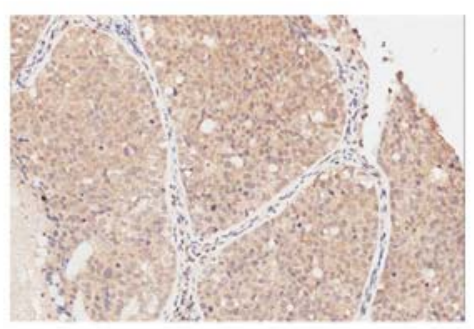

B Lung SCC pericarcinoma

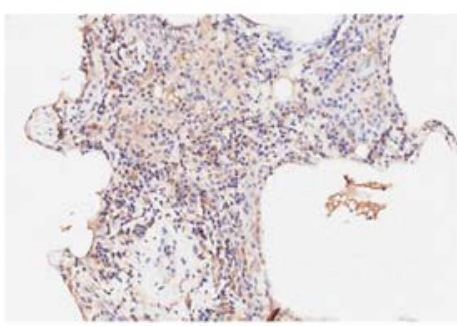

E Low expression of PTPRA

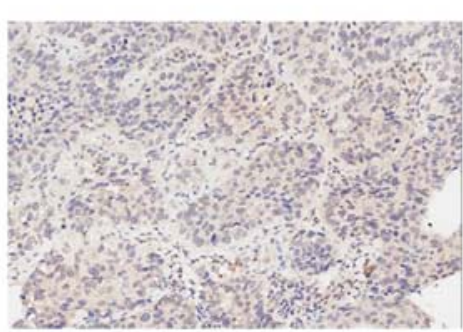

C

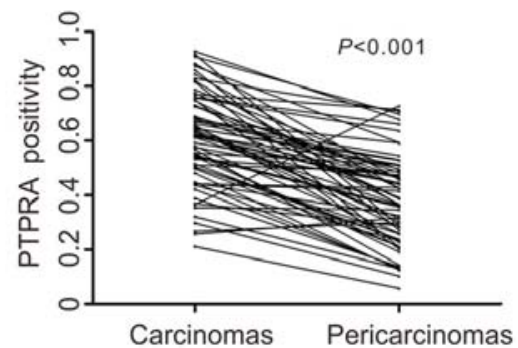

$\mathbf{F}$

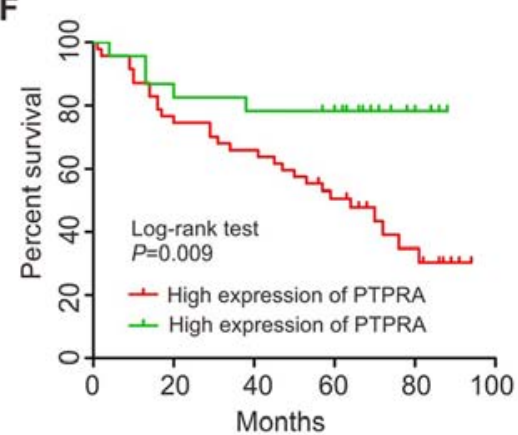

Figure 2. Survival risk prediction by expression profiles. (A and B) Profile of PTPRA immunostaining in lung SCC. Tissue stained with PTPRA antibody (1:800; Millipore). (C) Statistics of PTPRA expression in 75 paired lung SCC and adjacent normal tissues. (D and E) Representative images of high/low expression of PTPRA, shown respectively at x200 magnification. (F) Kaplan-Meier survival curves show high expression level of PTPRA was significantly correlated to poor survival of SCC in our data set. $\log$-rank test $\mathrm{P}=0.009$. 
Table II. The prognostic influence of PTPRA in SCC.

\begin{tabular}{|c|c|c|c|c|c|c|}
\hline \multirow[b]{2}{*}{ Prognostic parameter } & \multicolumn{3}{|c|}{ Univariate analysis } & \multicolumn{3}{|c|}{ Multivariate analysis } \\
\hline & HR & $95 \% \mathrm{CI}$ & P-value & HR & $95 \% \mathrm{CI}$ & P-value \\
\hline PTPRA (high vs. low) & 2.271 & $1.284-4.018$ & 0.005 & 2.306 & $1.189-4.469$ & 0.014 \\
\hline Age $(>65$ vs. $\leq 65)$ & 2.648 & $1.344-5.216$ & 0.005 & 2.895 & $1.430-5.859$ & 0.003 \\
\hline Sex (female vs. male) & 0.578 & $0.204-1.644$ & 0.305 & & & \\
\hline Tumor size, cm (>5 vs. $\leq 5)$ & 1.209 & $0.633-2.309$ & 0.566 & & & \\
\hline Tumor location (upper vs. lower) & 0.746 & $0.393-1.416$ & 0.370 & & & \\
\hline TNM stage (T1 vs. T2 vs. T3) & 1.411 & $0.889-2.238$ & 0.143 & & & \\
\hline Lymph node metastasis (present vs. absent) & 1.941 & $1.008-3.737$ & 0.048 & 1.229 & $0.516-2.921$ & 0.6412 \\
\hline Clinical stage & 1.804 & $1.175-2.768$ & 0.007 & 1.239 & $0.451-3.406$ & 0.6778 \\
\hline
\end{tabular}

HR, hazard ratio; CI, confidence interval. The bold number represents the P-value with significant differences.

A

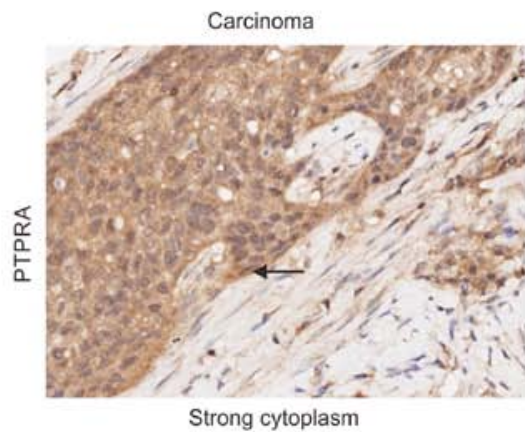

C

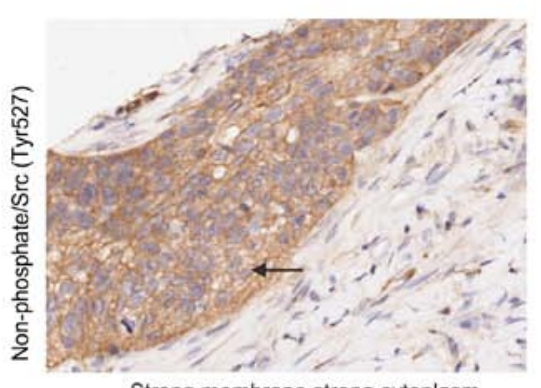

E

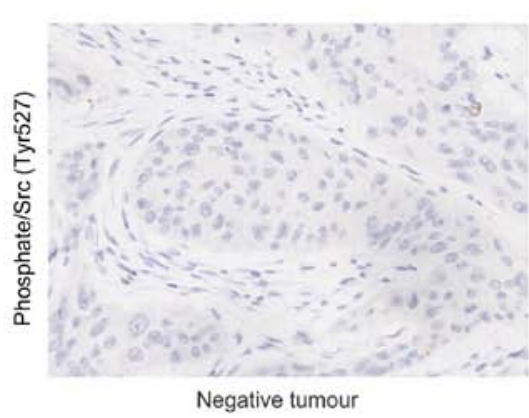

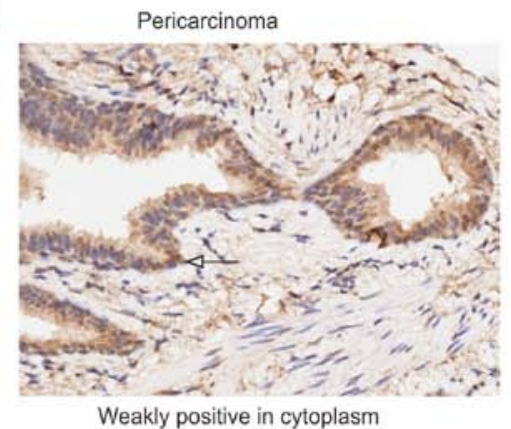

D

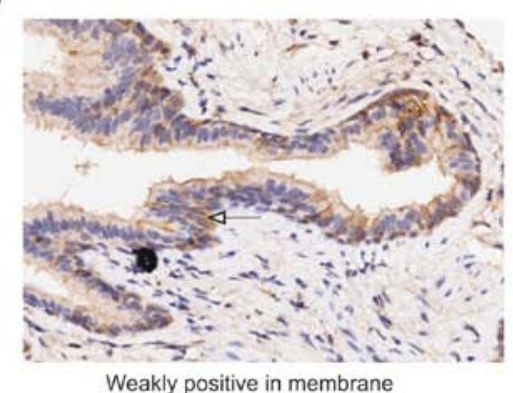

$\mathbf{F}$

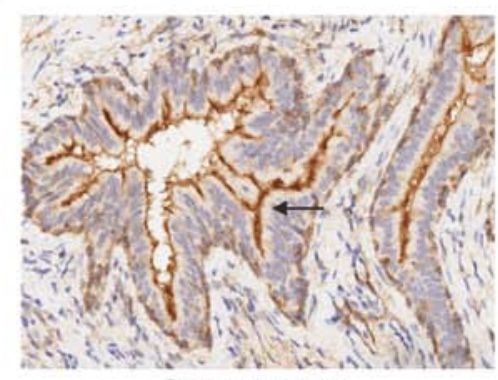

Strong membrane

G

\begin{tabular}{cccccc}
\hline \multicolumn{4}{c}{ non-phosphate/Sre (Tyr527) } & PABAK (95\% CI) & $P$ \\
\hline \multirow{3}{*}{ PTPRA } & High & High & Low & & \\
& Low & 4 & 2 & $0.61(-0.235 \sim 0.101)$ & 0.0002 \\
& & 11 & & \\
\hline
\end{tabular}

PABAK: $0.0 \sim 0.20$ slight agreement, $0.21 \sim 0.40$ fair agreement, $0.41 \sim 0.60$ moderate agreement, $0.61 \sim 0.80$ substantial agreement, $0.81 \sim 1.00$ perfect agreement.

Figure 3. PTPRA protein expression accompanied with Src activation in SCC cancer. Tissue stained with PTPRA antibody (1:800; Millipore), non-phosphate/ Src (Tyr527) (1:2,000; Cell Signaling Technology), Src Tyr527p antibody (1:200; Cell Signaling Technology). Representative images are shown at x400 magnification. 


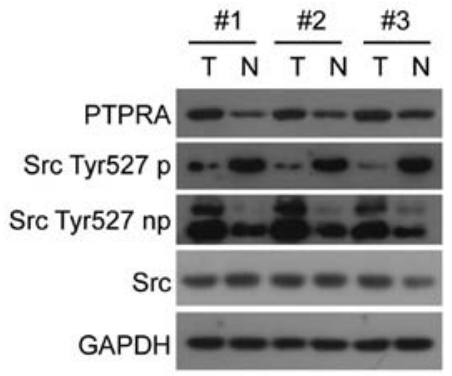

Figure 4. The expression of PTPRA protein in human SCC fresh frozen tissues. Total protein lysates from tumor or adjacent normal tissue from the same patient were subjected to anti-PTPRA immunoblotting, using an antiserum raised against the intracellular domain of PTPRA. Three representative pairs of tumor $(\mathrm{T})$ and neighboring normal tissue $(\mathrm{N})$ from the same patient are shown.

A

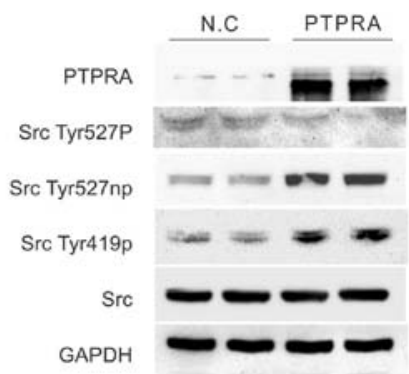

C

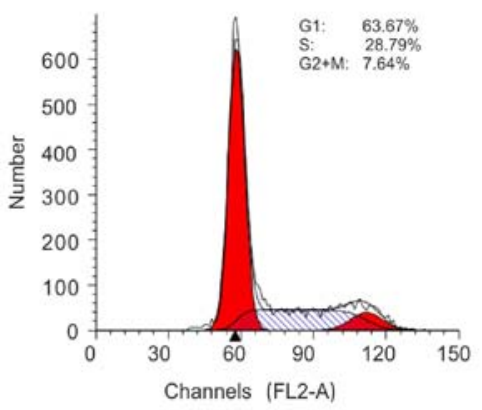

D

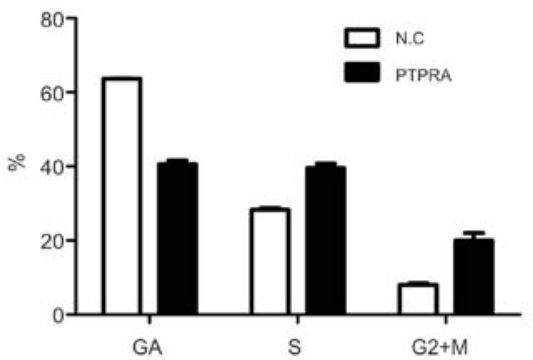

substantially increased in 14 out of the 20 tumor samples analyzed (70\%), whereas it was only marginally detectable in the matched normal neighbouring tissue. Three representative pairs of tumor $(\mathrm{T})$ and neighbouring normal tissue $(\mathrm{N})$ from the same-patient are shown in Fig. 4. PTPRA expression was elevated in SCC tissues, and its high expression levels accompanied with Src Tyr527 dephosphorylation, an indication of c-Src activation.

PTPRA overexpression promotes lung cancer cell growth through G1/S progression in vitro. To elucidate the consequences of PTPRA overexpression in the cellular proliferation, we overexpressed PTPRA in the H520 cells with the retroviral systems. As shown in Fig. 5A, overexpression of PTPRA led to the
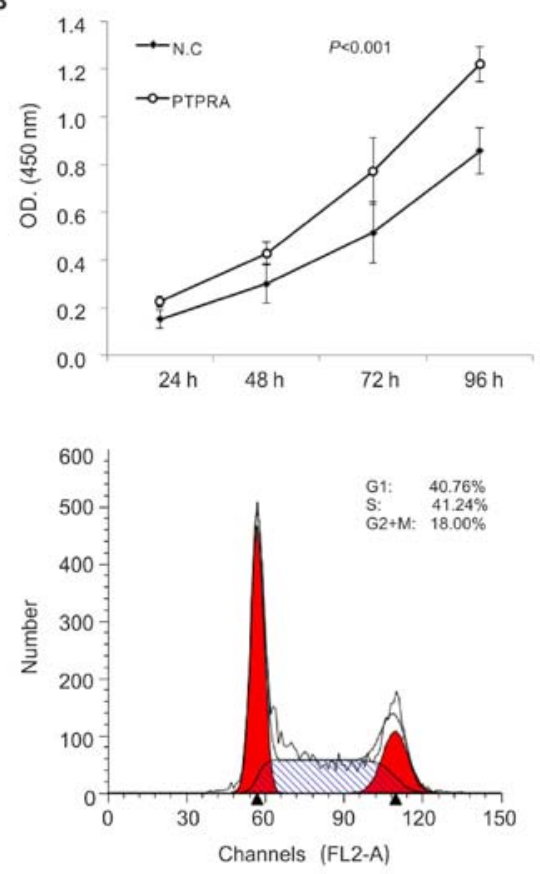

E

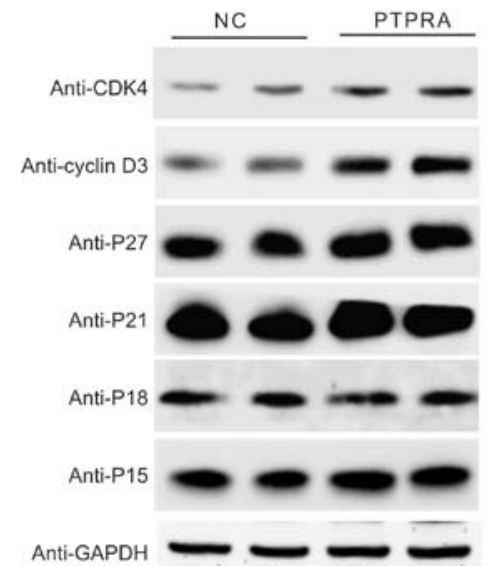

Figure 5. PTPRA overexpression promotes cell growth due to cell cycle arrest in lung cancer cells. (A) Immunoblot analysis of PTPRA expression in stably transfected H520 clones. Total protein lysates from an empty vector transfected clone (NC) and from one PTPRA cDNA transfected clone were immune blotted with anti-PTPRA. Activation of c-Src kinase activity, used as a result of PTPRA expression. Proteins were blotted with Src phosphorylation and dephosphorylation antisera. (B) Effect of PTPRA expression on the growth rate. The proliferation of stable H520 cell lines was examined using a Cell Counting kit. (C and D) Cell cycle distribution in an empty vector transfected clone (NC) and stable PTPRA expressing line. Exponentially growing cells were trypsinized, fixed, and stained with propidium iodide, and fluorescence measured by flow cytometry. (E) Cell cycle G1/S checkpoint signaling pathways were checked. Cells from an empty vector transfected clone (NC) and from one PTPRA cDNA transfected clones were lysed, and lysates were subjected to protein gel blot assays. The antibodies against p21, cyclin D1, cyclin D3, p27 and p18 were used to determine the effect of PTPRA upregulation on the activities of the cell cycle pathways. 
dephosphorylation of c-Src at Tyr527 but increased phosphorylation of c-Src at Tyr419, and the results were consistent with previous reports performed in other cell lines (29). The PTPRA stimulated the proliferation of the H520 cells as suggested by the MTT assays (Fig. 5B). In the cell cycle analyses, we found that the proportion of cells in $\mathrm{S}$ phase was significantly higher in the PTPRA overexpressed cell lines and the cells in the G0/G1 phase were significantly reduced (Fig. 5C and D), suggesting that PTPRA stimulated the G1/S transition in the SCC cells. To further clarify the underlying mechanisms of PTPRA in the regulating of cell cycle, we determined the influences of PTPRA in the cell cycle checkpoint signaling. As shown in Fig. 5E, increased PTPRA expression led to an increase of CDK4 and cyclin D3, which was suggested to be involved in the G1/S transition of the cells. No significant change in the expression of P27, $\mathrm{P} 21$, and P15 was found.

\section{Discussion}

In the present study, we analysed the clinical relevance of PTPRA with SCC patients, and found that PTPRA was significantly correlated with an aggressive phenotype of lung squamous cell carcinoma, including larger tumor size, later clinical stage, and a shorter overall survival time. We found that PTPRA overexpression can activate the c-Src signaling pathways and stimulate the G1/S transition in the cellular models. These results suggested that PTPRA acts as an oncogene in the development and progression of lung SCC.

To date, the roles of PTPRA in SCC carcinogenesis and tumor progression have not been fully elucidated. Most PTPs reported in lung cancer have revealed that they act as tumor suppressor genes, as they counteract the PTKs. PTPRB (30) was found to be downregulated in NSCLC, and knockdown of PTPRB increased Src phosphorylation and cell invasion. PTPN13 (31) was found to be a tumor suppressor candidate gene and it was frequently inactivated in NSCLC tissues through the loss of mRNA or protein expression level or the somatic mutation of the gene. Sequencing analysis of the PTPRD (32) gene revealed that it may act as a tumor suppressor that is frequently inactivated and mutated in lung cancer. In contrast with the other PTPs, PTPRA was increased in the SCC and higher expression was associated with poorer prognosis possibly due to its activities in c-Src. In vitro studies demonstrated that PTPRA plays important roles in the development of breast (11,33-35), gastric (36) and colon cancer $(17,37)$ through regulating the integrin signaling, cell adhesion, and Src family kinase tyrosine kinases signaling pathways. In the present study, we determined the relationship between PTPRA expression and activation state of c-Src in SCC samples and the cell line H520, which provided evidence that PTPRA expression has a potential to dephosphorylate the site of Tyr527 in PTK c-Src and activates the c-Src in SCC cells. These results provide evidence that high expression of PTPRA may dephosphorylate and activate c-Src, and might exert an oncogenic effect in the development of SCC.

The roles of PTPRA in SCC prognosis might be partially through regulating cellular proliferation. In the SCC cell line H520, the PTPRA overexpression led to the G1/S transition, which might result in the increased cellular proliferation. In cell cycle progression, increasing accumulations of cyclin
Cdk4/6 and cyclin A/E-Cdk2 complexes regulate the transition through G1 and synthetic phases (38). V-Src is capable of inducing cyclin D1 in MCF-7 cells $(39,40)$, c-Src was shown to have ability to regulate cell cycle via PI3K/Akt signaling-dependent and -independent mechanisms (41) and it was also reported to regulate cell cycle protein expression through extracellular signal-regulated kinases (42). However, it was still unclear to what extent c-Src activation by PTPRA is comparable to $\mathrm{V}$-Src expression for inducing cyclin proteins. Also, the arrest-inducing effect of PTPRA expression may partly or not be mediated through Src family kinases. We found that increased PTPRA expression induced cyclin D3 and CDK4 accumulation, and the underlying molecular mechanism needs further study.

High expression of PTPRA mRNA or protein levels have been found in oral squamous cell carcinoma (43), colon cancer $(37,44)$, breast cancer $(45)$ and gastric cancer $(46,47)$. In CRC cancer: Tabiti et al (44) observed a 2-10-fold increase of PTPRA mRNA levels in advanced colorectal carcinoma. They suggested the elevated PTPRA expression is unlikely to be a simple consequence of the hyperproliferative activity of the tumor cells, and high PTPRA expression level may be involved in the neoplastic transformation of colonic epithelial cells. At protein level, Krndija et al (37) found a negative expression level of PTPRA in the normal colorectal tissues, while $>70 \%$ of the colon cancer samples showed an increment of PTPRA expression. In gastric cancer: a genome-wide gene copy number and expression analysis of primary gastric tumors revealed PTPRA gene copy number increment in cancerous samples than non-malignant tissues (46). At protein level, Wu et al (47) demonstrated that higher PTPRA expression in gastric tumor was correlated with lympho-vascular invasion and liver/peritoneal dissemination. In breast cancer, the role of PTPRA was complex. Ardini et al (45) found higher PTPRA expression was correlated with lower tumor grade and positive ER status. The growth inhibition seen as a result of PTPRA expression is related to cell cycle arrest in G1. The authors reconciled the apparent conflict between the Src-activation and reduced growth in experimental tumor cells, with the reasons that high PTPRA expression in a subset of tumors is a remnant of an earlier disease stage, where it may have contributed to initiation, or early progression, but is lost at later stages in favour of more aggressive progression events. Consistent with a specific role of PTPRA in early stages of progression only, Meyer et al (35) demonstrated that PTPRA functions as a positive mediator of tumor initiation and maintenance in HER2/Neu-positive breast tumors.

In conclusion, this study demonstrated that PTPRA overexpression can serve as an independent predictor of poor clinical prognosis and decreased survival through c-Src activation. Therefore, PTPRA could be used as an important clinical marker and target for the treatment of lung SCC, however, more studies are warranted to fully elucidate the biological roles of PTPRA in lung SCC.

\section{Acknowledgements}

This study was supported by Shanghai Committee of Science and Technology, China (grant nos. 15ZR1426800 and 14411964500). 


\section{References}

1. Tonks NK: Protein tyrosine phosphatases: From genes, to function, to disease. Nat Rev Mol Cell Biol 7: 833-846, 2006.

2. Sun T, Aceto N, Meerbrey KL, Kessler JD, Zhou C, Migliaccio I, Nguyen DX, Pavlova NN, Botero M, Huang J, et al: Activation of multiple proto-oncogenic tyrosine kinases in breast cancer via loss of the PTPN12 phosphatase. Cell 144: 703-718, 2011.

3. Lin G, Aranda V, Muthuswamy SK and Tonks NK: Identification of PTPN23 as a novel regulator of cell invasion in mammary epithelial cells from a loss-of-function screen of the 'PTP-ome'. Genes Dev 25: 1412-1425, 2011.

4. Ying J, Li H, Cui Y, Wong AH, Langford $\mathrm{C}$ and Tao Q: Epigenetic disruption of two proapoptotic genes MAPK10/JNK3 and PTPN13/FAP-1 in multiple lymphomas and carcinomas through hypermethylation of a common bidirectional promoter. Leukemia 20: 1173-1175, 2006.

5. Hsu SH, Motiwala T, Roy S, Claus R, Mustafa M, Plass C, Freitas MA, Ghoshal K and Jacob ST: Methylation of the PTPRO gene in human hepatocellular carcinoma and identification of VCP as its substrate. J Cell Biochem 114: 1810-1818, 2013.

6. Nakamura M, Kishi M, Sakaki T, Hashimoto H, Nakase H, Shimada K, Ishida E and Konishi N: Novel tumor suppressor loci on 6q22-23 in primary central nervous system lymphomas. Cancer Res 63: 737-741, 2003.

7. Fridberg M, Kjellström S, Anagnostaki L, Skogvall I, Mustelin T, Wiebe T, Persson JL, Dictor M and Wingren AG: Immunohistochemical analyses of phosphatases in childhood B-cell lymphoma: Lower expression of PTEN and HePTP and higher number of positive cells for nuclear SHP2 in B-cell lymphoma cases compared to controls. Pediatr Hematol Oncol 25: 528-540, 2008 .

8. Denkert C, Schmitt WD, Berger S, Reles A, Pest S, Siegert A, Lichtenegger W, Dietel $M$ and Hauptmann S: Expression of mitogen-activated protein kinase phosphatase-1 (MKP-1) in primary human ovarian carcinoma. Int J Cancer 102: 507-513, 2002 .

9. Zhao S, Sedwick D and Wang Z: Genetic alterations of protein tyrosine phosphatases in human cancers. Oncogene 34: 3885-3894, 2015.

10. Nunes-Xavier CE, Elson A and Pulido R: Epidermal growth factor receptor (EGFR)-mediated positive feedback of proteintyrosine phosphatase epsilon (PTPepsilon) on ERK1/2 and AKT protein pathways is required for survival of human breast cancer cells. J Biol Chem 287: 3433-3444, 2012.

11. Boivin B, Chaudhary F, Dickinson BC, Haque A, Pero SC, Chang CJ and Tonks NK: Receptor protein-tyrosine phosphatase $\alpha$ regulates focal adhesion kinase phosphorylation and ErbB2 oncoprotein-mediated mammary epithelial cell motility. J Biol Chem 288: 36926-36935, 2013

12. Wang J, Chen X, Liu B and Zhu Z: Suppression of PTP1B in gastric cancer cells in vitro induces a change in the genome-wide expression profile and inhibits gastric cancer cell growth. Cell Biol Int 34: 747-753, 2010.

13. Wang N, She J, Liu W, Shi J, Yang Q, Shi B and Hou P: Frequent amplification of PTP1B is associated with poor survival of gastric cancer patients. Cell Cycle 14: 732-743, 2015.

14. Matozaki T, Murata Y, Saito Y, Okazawa H and Ohnishi H Protein tyrosine phosphatase SHP-2: A proto-oncogene product that promotes Ras activation. Cancer Sci 100: 1786-1793, 2009.

15. Zeng LF, Zhang RY, Yu ZH, Li S, Wu L, Gunawan AM, Lane BS, Mali RS, Li X, Chan RJ, et al: Therapeutic potential of targeting the oncogenic SHP2 phosphatase. J Med Chem 57: 6594-6609, 2014.

16. Li SM: The biological function of shp2 in human disease. Mol Biol (Mosk) 50: 27-33, 2016 (In Russian).

17. Huang J, Yao L, Xu R, Wu H, Wang M, White BS, Shalloway D and Zheng X: Activation of Src and transformation by an RPTP $\alpha$ splice mutant found in human tumours. EMBO J 30: 3200-3211, 2011.

18. Truffi M, Dubreuil V, Liang X, Vacaresse N, Nigon F, Han SP, Yap AS, Gomez GA and Sap J: RPTP $\alpha$ controls epithelial adherens junctions, linking E-cadherin engagement to c-Srcmediated phosphorylation of cortactin. J Cell Sci 127: 2420-2432, 2014.

19. Cheng SY, Sun G, Schlaepfer DD and Pallen CJ: Grb2 promotes integrin-induced focal adhesion kinase (FAK) autophosphorylation and directs the phosphorylation of protein tyrosine phosphatase $\alpha$ by the Src-FAK kinase complex. Mol Cell Biol 34: 348-361, 2014
20. Buist A, Blanchetot C, Tertoolen LG and den Hertog J: Identification of p130cas as an in vivo substrate of receptor protein-tyrosine phosphatase alpha. J Biol Chem 275: 20754-20761, 2000

21. Lai X, Chen Q, Zhu C, Deng R, Zhao X, Chen C, Wang Y, Yu J and Huang J: Regulation of RPTP $\alpha$-c-Src signalling pathway by miR-218. FEBS J 282: 2722-2734, 2015.

22. Vacaresse N, Møller B, Danielsen EM, Okada M and Sap J: Activation of c-Src and Fyn kinases by protein-tyrosine phosphatase RPTPalpha is substrate-specific and compatible with lipid raft localization. J Biol Chem 283: 35815-35824, 2008.

23. Elsberger B, Fullerton R, Zino S, Jordan F, Mitchell TJ, Brunton VG, Mallon EA, Shiels PG and Edwards J: Breast cancer patients' clinical outcome measures are associated with Src kinase family member expression. Br J Cancer 103: 899-909, 2010.

24. Elsberger B, Tan BA, Mallon EA, Brunton VG and Edwards J: Is there an association with phosphorylation and dephosphorylation of Src kinase at tyrosine 530 and breast cancer patient disease-specific survival. Br J Cancer 103: 1831-1834, 2010

25. Qayyum T, McArdle PA, Lamb GW, Jordan F, Orange C, Seywright M, Horgan PG, Jones RJ, Oades G, Aitchison MA, et al: Expression and prognostic significance of Src family members in renal clear cell carcinoma. Br J Cancer 107: 856-863, 2012.

26. Roskoski R Jr: Src kinase regulation by phosphorylation and dephosphorylation. Biochem Biophys Res Commun 331: 1-14, 2005.

27. Tryfonopoulos D, Walsh S, Collins DM, Flanagan L, Quinn C, Corkery B, McDermott EW, Evoy D, Pierce A, O'Donovan N, et al: Src: A potential target for the treatment of triple-negative breast cancer. Ann Oncol 22: 2234-2240, 2011.

28. Győrffy B, Surowiak P, Budczies J and Lánczky A: Online survival analysis software to assess the prognostic value of biomarkers using transcriptomic data in non-small-cell lung cancer. PLoS One 8: e82241, 2013.

29. den Hertog J, Pals CE, Peppelenbosch MP, Tertoolen LG, de Laat SW and Kruijer W: Receptor protein tyrosine phosphatase alpha activates pp60c-src and is involved in neuronal differentiation. EMBO J 12: 3789-3798, 1993.

30. Qi Y, Dai Y and Gui S: Protein tyrosine phosphatase PTPRB regulates Src phosphorylation and tumour progression in NSCLC. Clin Exp Pharmacol Physiol 43: 1004-1012, 2016.

31. Scrima M, De Marco C, De Vita F, Fabiani F, Franco R, Pirozzi G, Rocco G, Malanga D and Viglietto G: The nonreceptor-type tyrosine phosphatase PTPN13 is a tumor suppressor gene in non-small cell lung cancer. Am J Pathol 180: 1202-1214, 2012.

32. Veeriah S, Brennan C, Meng S, Singh B, Fagin JA, Solit DB, Paty PB, Rohle D, Vivanco I, Chmielecki J, et al: The tyrosine phosphatase PTPRD is a tumor suppressor that is frequently inactivated and mutated in glioblastoma and other human cancers. Proc Natl Acad Sci USA 106: 9435-9440, 2009.

33. Lucci MA, Orlandi R, Triulzi T, Tagliabue E, Balsari A and Villa-Moruzzi E: Expression profile of tyrosine phosphatases in her 2 breast cancer cells and tumors. Cell Oncol 32: 361-372, 2010.

34. Tremper-Wells B, Resnick RJ, Zheng X, Holsinger LJ and Shalloway D: Extracellular domain dependence of PTPalpha transforming activity. Genes Cells 15: 711-724, 2010

35. Meyer DS, Aceto N, Sausgruber N, Brinkhaus H, Muller U, Pallen CJ and Bentires-Alj M: Tyrosine phosphatase PTPo contributes to HER2-evoked breast tumor initiation and maintenance. Oncogene 33: 398-402, 2014

36. Yahiro K, Wada A, Nakayama M,Kimura T, Ogushi K, Niidome T, Aoyagi H, Yoshino K, Yonezawa K, Moss J, et al: Protein-tyrosine phosphatase alpha, RPTP alpha, is a Helicobacter pylori VacA receptor. J Biol Chem 278: 19183-19189, 2003.

37. Krndija D, Schmid H, Eismann JL, Lother U, Adler G, Oswald F, Seufferlein T and von Wichert G: Substrate stiffness and the receptor-type tyrosine-protein phosphatase alpha regulate spreading of colon cancer cells through cytoskeletal contractility. Oncogene 29: 2724-2738, 2010.

38. Mueller PR, Coleman TR, Kumagai A and Dunphy WG: Myt1: A membrane-associated inhibitory kinase that phosphorylates Cdc2 on both threonine-14 and tyrosine-15. Science 270: 86-90, 1995.

39. Lee RJ, Albanese C, Stenger RJ, Watanabe G, Inghirami G, Haines GK III, Webster M, Muller WJ, Brugge JS, Davis RJ, et al: pp60(v-src) induction of cyclin D1 requires collaborative interactions between the extracellular signal-regulated kinase, $\mathrm{p} 38$, and Jun kinase pathways. A role for cAMP response element-binding protein and activating transcription factor- 2 in pp60(v-src) signaling in breast cancer cells. J Biol Chem 274: $7341-7350,1999$. 
40. Riley D, Carragher NO, Frame MC and Wyke JA: The mechanism of cell cycle regulation by v-Src. Oncogene 20: 5941-5950, 2001.

41. Xing J, Zhang Z, Mao H, Schnellmann RG and Zhuang S: Src regulates cell cycle protein expression and renal epithelial cell proliferation via PI3K/Akt signaling-dependent and -independent mechanisms. Am J Physiol Renal Physiol 295: F145-F152, 2008.

42. Liu X, Du L and Feng R: c-Src regulates cell cycle proteins expression through protein kinase B/glycogen synthase kinase 3 beta and extracellular signal-regulated kinases 1/2 pathways in MCF-7 cells. Acta Biochim Biophys Sin (Shanghai) 45: 586-592, 2013.

43. Berndt A, Luo X, Böhmer FD and Kosmehl H: Expression of the transmembrane protein tyrosine phosphatase RPTPalpha in human oral squamous cell carcinoma. Histochem Cell Biol 111: 399-403, 1999.
44. Tabiti K, Smith DR, Goh HS and Pallen CJ: Increased mRNA expression of the receptor-like protein tyrosine phosphatase alpha in late stage colon carcinomas. Cancer Lett 93: 239-248, 1995.

45. Ardini E, Agresti R, Tagliabue E, Greco M, Aiello P, Yang LT, Ménard S and Sap J: Expression of protein tyrosine phosphatase alpha (RPTPalpha) in human breast cancer correlates with low tumor grade, and inhibits tumor cell growth in vitro and in vivo. Oncogene 19: 4979-4987, 2000.

46. Junnila S, Kokkola A, Karjalainen-Lindsberg ML,Puolakkainen P and Monni O: Genome-wide gene copy number and expression analysis of primary gastric tumors and gastric cancer cell lines. BMC Cancer 10: 73, 2010

47. Wu CW, Kao HL, Li AF, Chi CW and Lin WC: Protein tyrosinephosphatase expression profiling in gastric cancer tissues. Cancer Lett 242: 95-103, 2006. 